Bärbel Richter • Karolin Stegmann • Britta Röper

Inke Böddeker • Ernestine T.K.M. Ngo

Manuela C. Koch

\title{
Interaction of folate and homocysteine pathway genotypes evaluated in susceptibility to neural tube defects (NTD) in a German population
}

\begin{abstract}
Neural tube defects (NTD) are likely to result from an interaction of several genes and environmental factors. Because periconceptional folate intake reduces the NTD risk in the fetus, and because mothers of children with NTD showed elevated plasma homocysteine levels, gene polymorphisms of the folate and homocysteine pathway, such as 5,10-methylenetetrahydrofolate reductase $($ MTHFR ) 677C $\rightarrow \mathrm{T}$, MTHFR $1298 \mathrm{~A} \rightarrow \mathrm{C}$ and cystathionine $\beta$-synthase $(C B S)$ 844ins68, have been implicated in the etiology of NTD. Several studies have demonstrated that these polymorphisms may indeed be associated with NTD in some populations. In order to evaluate the role of these polymorphisms and their interaction in NTD, we genotyped 417 individuals for case-control studies and 129 families for transmission disequilibrium tests. We are the first to present detailed data on MTHFR haploid genotypes in combination with $C B S$ 844ins68. The $M T H F R$ risk genotype 677CT/1298AC, known to be associated with decreased enzyme activity and increased homocysteine, was found significantly more often in patients than in controls $(P=$ 0.02). A CBS insertion allele in addition to $M T H F R$ 677CT/ 1298AC heterozygosity or MTHFR 677TT/1298AA homozygosity did not result in an increased risk for NTD. This is in agreement with the recently reported homocysteine-lowering effect of the $C B S$ 844ins68 allele in carriers of $M T H F R$ variants.
\end{abstract}

Key words Neural tube defects * MTHFR $677 \mathrm{C} \rightarrow \mathrm{T}$. MTHFR $1298 \mathrm{~A} \rightarrow \mathrm{C}$. Cystathionine $\beta$-synthase $\cdot C B S$ 844 ins $68 \cdot$ Genotype interaction

B. Richter · K. Stegmann · B. Röper · E.T.K.M. Ngo

M.C. Koch $(\square)$

Zentrum für Humangenetik, Bahnhofstraße 7, D-35037 Marburg, Germany

Tel. +49-6421-286-6269; Fax +49-6421-286-8920

e-mail: koch2@mailer.uni-marburg.de

I. Böddeker

Zentrum für Methodenwissenschaften und Gesundheitsforschung, Institut für Medizinische Biometrie und Epidemiologie, Philipps-

Universität Marburg, Marburg, Germany

\section{Introduction}

Nonsyndromic neural tube defects (NTD) are among the most frequent congenital malformations, with an estimated prevalence at birth of about 1:1000 in most populations. NTD are thought to be of multifactorial origin, involving a number of as yet unknown genetic and environmental factors. Randomized trials in different populations have demonstrated that the occurrence and recurrence risk of NTD is reduced by folic acid supplementation taken during the periconceptional period (Berry et al. 1999; Czeizel and Dudás 1992; MRC Vitamin Study Research Group 1991). The protective effect of folic acid has led to a search for candidate genes involved in its metabolic pathway. The enzymes 5,10-methylenetetrahydrofolate reductase (MTHFR) and cystathionine $\beta$-synthase (CBS), are promising candidates for folate-sensitive NTD, accounting for about $70 \%$ of human NTD. Both enzymes participate in the folate-dependent metabolism of homocysteine, and genetic defects in these enzymes can cause hyperhomocysteinemia, which has been found in mothers of NTD-affected children (Mills et al. 1995). Because hyperhomocysteinemia is correctable by folic acid intake (Kang et al. 1988), it has been speculated that decreasing the plasma homocysteine level might be the mechanism responsible for the NTDpreventive effect of folic acid (Mills et al. 1996; Piedrahita et al. 1999).

MTHFR catalyzes the reduction of 5,10-methylenetetrahydrofolate (THF) to 5-methyl-THF, which is required as a cosubstrate in the remethylation of homocysteine to methionine. The thermolabile variant of MTHFR due to the common polymorphism $677 \mathrm{C} \rightarrow \mathrm{T}$ has reduced enzyme activity (Frosst et al. 1995; van der Put et al. 1995), resulting in mild hyperhomocysteinemia, especially if the folate status is poor (Jacques et al. 1996). It has therefore been postulated that 677TT-homozygotes have an increased folate requirement to regulate their homocysteine levels (Molloy et al. 1997). Initial investigations showed that this polymorphism may be associated with NTD in some populations. A significant increase in the 677TT homozygosity rate in NTD 
cases compared with controls was independently reported in the Irish and Dutch populations (van der Put et al. 1995; Whitehead et al. 1995). Subsequent population-based studies have confirmed the association of TT-homozygosity and NTD (de Franchis et al. 1998; Shields et al. 1999), although other studies of similar design have failed to do so (Morrison et al. 1998; Speer et al. 1997; Stegmann et al. 1999). Recently, it was suggested that a second MTHFR polymorphism, 1298A $\rightarrow$ C, confers an additional NTD risk. Combined heterozygosity of MTHFR 677CT/1298AC tended to be more frequent in Dutch NTD patients than in controls, although without reaching significance (odds ratio [OR], 2.04; 95\% confidence interval [CI], 0.89-4.70; van der Put et al. 1998). Individuals with this genotype combination showed reduced MTHFR activity, elevated plasma homocysteine, and decreased plasma folate, although these features were less pronounced than in 677TT homozygotes (van der Put et al. 1998). Data for other populations failed to confirm an association between NTD and MTHFR 677CT/1298AC (Barber et al. 2000; Stegmann et al. 1999; Trembath et al. 1999).

Because failure of human neural tube closure is likely to result from an interaction of several genes, the cystathionine $\beta$-synthase $(C B S)$ polymorphism 844 ins 68 has been investigated as an additional risk factor in NTD. All studies so far have found that $C B S$ 844ins68 alone was not associated with NTD (Akar et al. 2000; de Franchis et al. 1997; Morrison et al. 1998; Ramsbottom et al. 1997; Speer et al. 1999). Regarding a possible gene-gene interaction between $M T H F R$ and $C B S$, the results were conflicting. Three casecontrol studies were unable to reveal a significant association of MTHFR 677TT homozygosity in conjunction with $C B S$ 844ins68 heterozygosity and NTD (Morrison et al. 1998; Ramsbottom et al. 1997; Speer et al. 1999). However, in the Italian sample, NTD patients homozygous for 677TT significantly more often carried an additional $C B S$ 844ins68 allele than 677TT controls (de Franchis et al. 1997). In the American study, the difference in MTHFR-CBS combination data between patients and controls became significant after pooling with Irish controls (Speer et al. 1999). It seems that the $C B S$ 844ins68 allele acts as an additional risk factor for NTD, at least in some populations. In order to evaluate a synergistic involvement of these folate and homocysteine pathway genotypes in German NTD cases, we investigated the distributions of the two MTHFR genotypes and $C B S$ 844ins68 separately, and in combination with each other, in patients, their parents, and controls. According to our results there was no statistically significant association for any of the polymorphisms when evaluated separately. However, our data provide evidence for an interaction between the MTHFR polymorphisms, because the frequency of the compound MTHFR genotype 677CT/1298AC is significantly increased in NTD cases. The coexistence of a $C B S$ insertion allele with MTHFR 677TT/1298AA or CT/AC did not result in an increased risk for NTD.

\section{Methods}

Probands and controls

The study group consisted of 184 German patients (169 nonfamilial, 15 familial) with a non-syndromic neural tube defect ( 9 anencephalics, 3 encephaloceles, 172 spina bifida aperta). Spina bifida aperta (SBA) families were recruited from an ambulatory Spina bifida clinic, and fetuses were obtained from the fetal pathology unit of our medical center. The control population consisted of 233 unrelated healthy German volunteers (males and females).

For the case-control association study, all NTD patients and control subjects were genotyped for $M T H F R 677 \mathrm{C} / \mathrm{T}$, MTHFR $1298 \mathrm{~A} / \mathrm{C}$, and CBS 844ins68. For the family-based association study, 98 trios (mother, father, SBA child) and 31 parent-offspring pairs were genotyped to investigate transmission disequilibrium of the $M T H F R$ and $C B S$ alleles.

The study was approved by the Ethics Committee of the University of Marburg, and informed consent was obtained from patients, parents, and control individuals.

\section{DNA analysis}

Genotyping for MTHFR $677 \mathrm{C} / \mathrm{T}$ and $1298 \mathrm{~A} / \mathrm{C}$ was done as described by Stegmann et al. (1999), including an amplification refractory mutation system (ARMS) test to determine the haplotype of all individuals heterozygous at both MTHFR sites (677CT-1298AC). Genotyping for CBS 844 ins68 was performed using primers previously reported by Ramsbottom et al. (1997). The 68-bp insertion in exon 10 of $C B S$ was reported to cosegregate with the frequent mutation 833T $\rightarrow$ C (I278T) in cis (Kozich and Kraus 1992; Kraus et al. 1998; Tsai et al. 1996). We verified the $833 \mathrm{C} \rightarrow \mathrm{T}$ nucleotide exchange on all insertion alleles by digesting the polymerase chain reaction (PCR) product with the restriction enzyme BsrI, as described by Kozich and Kraus (1992).

\section{Statistics}

The distributions of genotypes and genotype combinations in cases and controls were compared using Fisher's onesided exact test at a 5\% significance level. The transmission disequilibrium test (TDT) was applied to analyze transmission disequilibrium in trios and parent-offspring pairs (Sun et al. 1999).

\section{Results}

MTHFR genotypes $677 \mathrm{C} / \mathrm{T}-1298 \mathrm{~A} / \mathrm{C}$ in combination with $C B S$ genotype 844 ins 68 for cases and controls $(n=184+$ $233=417)$ are given in Table 1 .

Observed frequencies of the 677TT genotype (677T allele) were 28/184 (15.2\%) (0.38) in cases and 27/233 
Table 1. Combinations of $M T H F R$ 677C/T-1298A/C haploid genotypes with $C B S$ 844ins68 genotypes in 184 patients $^{\mathrm{a}}$ and 233 controls

\begin{tabular}{|c|c|c|c|c|c|c|c|}
\hline \multicolumn{3}{|c|}{ MTHFR } & $C B S$ & wt-ins & ins-ins & \multicolumn{2}{|l|}{ Total } \\
\hline 677 & $\mathrm{C}$ & $\mathrm{C}$ & 32 & 8 & 1 & 41 & Controls \\
\hline 1298 & A & A & 17 & 2 & 0 & 19 & Patients \\
\hline 677 & $\mathrm{C}$ & $\mathrm{C}$ & 36 & 9 & 2 & 47 & Controls \\
\hline 1298 & A & $\mathrm{C}$ & 33 & 8 & 1 & 42 & Patients \\
\hline 677 & $\mathrm{C}$ & $\mathrm{C}$ & 22 & 3 & 0 & 25 & Controls \\
\hline 1298 & $\mathrm{C}$ & $\mathrm{C}$ & 10 & 2 & 0 & 12 & Patients \\
\hline 677 & $\mathrm{C}$ & $\mathrm{T}$ & 42 & 13 & 0 & 55 & Controls \\
\hline 1298 & A & A & 35 & 3 & 0 & 38 & Patients \\
\hline 677 & $\mathrm{C}$ & $\mathrm{T}$ & 34 & 4 & 0 & 38 & Controls \\
\hline 1298 & C & A & 41 & 4 & 0 & 45 & Patients \\
\hline 677 & $\mathrm{~T}$ & $\mathrm{~T}$ & 25 & 2 & 0 & 27 & Controls \\
\hline 1298 & A & A & 26 & 2 & 0 & 28 & Patients \\
\hline
\end{tabular}

MTHFR haplotype frequencies

\begin{tabular}{|c|c|c|}
\hline $\mathrm{T}$ & $147 / 466=0.32$ & Controls \\
\hline A & $139 / 368=0.38$ & Patients \\
\hline $\mathrm{C}$ & $184 / 466=0.39$ & Controls \\
\hline A & $118 / 368=0.32$ & Patients \\
\hline $\mathrm{C}$ & $135 / 466=0.29$ & Controls \\
\hline $\mathrm{C}$ & $111 / 368=0.30$ & Patients \\
\hline
\end{tabular}

MTHFR, 5,10-Methylenetetrahydrofolate reductase gene; $C B S$, cystathione $\beta$-synthase gene; wt, wild-type; ins, insertion

a including: 9 anencephalic cases: $1 \times \mathrm{CC} / \mathrm{AA}-\mathrm{wt} / \mathrm{wt}, 1 \times \mathrm{CC} / \mathrm{AC}-$ wt/ins, $2 \times \mathrm{CT} / \mathrm{AA}-\mathrm{wt} / \mathrm{wt}, 3 \times \mathrm{CT} / \mathrm{AC}-\mathrm{wt} / \mathrm{wt}, 2 \times \mathrm{TT} / \mathrm{AA}-$ $\mathrm{wt} / \mathrm{wt}$ and 3 encephalic cases: $2 \times \mathrm{CC} / \mathrm{AA}-\mathrm{wt} / \mathrm{wt}, 1 \times \mathrm{CT} / \mathrm{AA}-$ $\mathrm{wt} / \mathrm{wt}$

(11.6\%) (0.32) in controls, and observed frequencies of the 1298CC genotype (1298C allele) were $12 / 184$ (6.5\%) (0.30) in cases and 25/233 (10.7\%) (0.29) in controls. Comparison of patients with controls revealed no significant difference in 677TT $(P=0.16)$ and $1298 \mathrm{CC}(P=0.08)$ homozygosity. Analyses of the 98 family trios and the 31 parent-offspring pairs failed to detect transmission disequilibrium for the 677T-allele (transmitted:nontransmitted, 57:57; $P=1.00$ ) and the $1298 \mathrm{C}$-allele $(52: 53 ; P=1.00)$.

The MTHFR genotype combinations 677CT/1298CC, TT/AC, and TT/CC were not observed (Stegmann et al. 1999; van der Put et al. 1998). All individuals homozygous for one MTHFR mutation were homozygous wild-type for the other (677TT/1298AA and CC/CC). Haplotyping proved that combined heterozygotes always carried the two mutations in trans (677CT/1298AC). The frequency of this compound heterozygous genotype $\mathrm{CT} / \mathrm{AC}$ was significantly increased in patients $(45 / 184)$ compared with controls (38/ 233; $P=0.02$ ).

We found $C B S$ 844ins68 heterozygosity (homozygosity) in $21 / 184 ; 11.4 \%(1 / 184 ; 0.5 \%)$ of cases and in $39 / 233 ; 16.7 \%$ $(3 / 233 ; 1.3 \%)$ of controls. In all CBS 844ins68 alleles, the $833 \mathrm{~T} \rightarrow \mathrm{C}$ mutation was found in cis. There was no significant difference in $C B S$ genotype distribution (insertion
Table 2. $C B S$ 844ins68 evaluated as an additional risk factor in individuals with selected $M T H F R$ genotypes

\begin{tabular}{|c|c|c|c|c|c|c|}
\hline \multicolumn{3}{|c|}{$\begin{array}{l}M T H F R \text { risk } \\
\text { genotypes }\end{array}$} & $C B S$ & \multirow{2}{*}{$\frac{\text { Cases }}{26 / 28}$} & \multirow{2}{*}{$\begin{array}{l}\text { Controls } \\
25 / 27\end{array}$} & \multirow{2}{*}{$\frac{P}{1.00}$} \\
\hline 677 & $\mathrm{~T}$ & $\mathrm{~T}$ & wt-wt & & & \\
\hline 1298 & $\mathrm{~A}$ & A & wt-ins & $2 / 28$ & $2 / 27$ & \\
\hline 677 & $\mathrm{C}$ & $\mathrm{T}$ & wt-wt & $41 / 45$ & $34 / 38$ & 1.00 \\
\hline 1298 & C & A & wt-ins & $4 / 45$ & $4 / 38$ & \\
\hline
\end{tabular}

[ins]/ins + wild-type [wt]/ins) comparing patients (22/184) and controls $(42 / 233, P=0.051)$. Analysis of the trios and parent-offspring pairs revealed no transmission disequilibrium (transmitted:nontransmitted, 14:16; $P=1.00$ ). The overall insertion allele frequency in the 417 individuals was $0.082(68 / 834)$.

All $C B S$ 844ins68 homozygotes were MTHFR $677 \mathrm{CC}$. The lack of a $677 \mathrm{~T}$ allele in combination with homozygosity for $C B S$ 844ins68 is probably due to the low population frequency of the insertion allele and not to a true linkage disequilibrium. To evaluate a $C B S-M T H F R$ gene-gene interaction, we tested whether patients with the MTHFR genotypes 677TT/1298AA or CT/AC more frequently carried additional $C B S$ 844ins68 alleles than controls (Table 2). The coexistence of a $C B S$ insertion allele with MTHFR TT/ $\mathrm{AA}$ or $\mathrm{CT} / \mathrm{AC}$ genotype did not result in an increased risk for NTD $(P=1.00)$.

\section{Discussion}

The mechanism by which low folate and elevated homocysteine disrupt neural tube development in humans is still unexplained. For the targeted Cart1 knockout mouse and the spontaneously arisen Splotch phenotype, folic acid treatment has been reported to decrease the risk of NTD (Fleming and Copp 1998; Zhao et al. 1996). However, folate deficiency alone did not lead to NTD in mice (Heid et al. 1992), consistent with the well supported hypothesis that the preventive effect consists not simply of compensating a nutritional deficiency (Mills et al. 1996). Possibly, folate acts by lowering homocysteine. High doses of homocysteine can induce NTD in chicken embryos, a teratogenic effect that is preventable by folic acid (Rosenquist et al. 1996). The results of these experiments in animal models have encouraged the examination of functional relevant gene polymorphisms of the folate and homocysteine pathway in relation to human NTD.

Population-based association studies of single polymorphisms have produced conflicting data, probably due to phenotypic heterogeneity, ethnic differences in genotype distributions, and the polygenic etiology in NTD. Therefore, in the present study, we took into consideration the different phenotypes and used ethnically homogeneous case-control groups. With regard to the polygenic etiology, we especially focused on the impact of possible interactions between folate and homocysteine pathway genotypes. 
Three polymorphisms were investigated: $M T H F R$ $677 \mathrm{C} \rightarrow \mathrm{T}$, MTHFR $1298 \mathrm{~A} \rightarrow \mathrm{C}$, and CBS 844ins68.

Comparing NTD patients with controls, we found no significant difference in allele and genotype frequencies for any polymorphism regarded separately (Table 1). Similarily, our family-based analyses detected no linkage disequilibrium. The lack of association between the single MTHFR genotypes and German NTD cases is in agreement with our previous results and with data from other studies (Boduroglu et al. 1999; Mornet et al. 1997; Morrison et al. 1998; Shaw et al. 1998). Our MTHFR genotype and allele frequencies showed intermediate values, comparable to frequencies in North European-derived populations (Botto and Yang 2000; Fletcher and Kessling 1998).

So far, only a few studies have looked for an association between the $C B S$ insertion allele and NTD in Caucasians (Akar et al. 2000; de Franchis et al. 1997; Morrison et al. 1998; Ramsbottom et al. 1997; Speer et al. 1999). As in our present study, none of them found an association. We found a rate of $C B S$ 844ins 68 homozygosity of $0.96 \%$ (4/417 individuals), corresponding well to the expected proportion, given the insertion allele frequency of 0.08 . Our low homozygosity rate is in agreement with population data demonstrating that $C B S$ 844ins68 homozygosity is rare in black Africans (4\%) and nearly absent in Europeans and Asians (less than 1\%) (Franco et al. 1998; Pepe et al. 1999).

In a combined analysis, we detected a significantly increased frequency of the MTHFR haploid genotype 677CT/ 1298 AC among patients compared with controls $(P=0.02)$. Therefore, in contrast to our previous study, our data now provide evidence for an interaction between both $M T H F R$ polymorphisms. In our 1999 study, we presented the more conservative two-sided $P$ values, whereas we now give onesided $P$ values. However, for the present study, even the two-sided test resulted in a $P$ value of less than 0.05 . Exclusion of the cranial phenotypes $(n=12)$ from all computations did not change statistical significance.

A comparison with findings in the literature is difficult, because our data consist of experimentally established haploid genotypes, whereas in other studies the 677CT/1298AC genotypes are mostly inferred from the absent combinations 677CT/1298CC, 677TT/1298AC, and 677TT/1298CC. Although the risk genotype 677CT/1298AC was proposed by van der Put et al. (1998), the Dutch and American data so far have failed to show unambigious significance (Barber et al. 2000; Trembath et al. 1999; van der Put et al. 1998). Our study is the first to present reliable and statistically significant data for an association of MTHFR risk genotypes with NTD. The risk genotypes 677TT/1298AA and CT/AC may be of biological significance, because they have been shown to be associated with decreased MTHFR enzyme activity and elevated plasma homocysteine (Weisberg et al. 1998).

Another important enzyme in the control of plasma homocysteine levels is CBS, which catalyzes the first step in the catabolic pathway. In order to explore a possible $M T H F R-C B S$ gene-gene interaction as an NTD risk factor, we tested whether the MTHFR risk genotypes 677TT/ 1298AA and CT/AC were associated with an additional
CBS 844ins68 allele in NTD patients (Table 2). In contrast to the Italian study (de Franchis et al. 1997), but in agreement with other studies (Morrison et al. 1998; Ramsbottom et al. 1997; Speer et al. 1999), we could not detect an additional risk conferred by the $C B S$ insertion allele $(P=1.00)$. After pooling their own American group with published Irish controls, Speer et al. (1999) found a significant effect. However, pooling groups of different ethnic origin appears problematic in association studies sensitive to stratification effects.

The lack of association of $C B S$ 844ins68 with NTD should be regarded in context with recent findings that the insertion allele is not associated with increased homocysteine plasma levels. Instead, hyperhomocysteinemia due to thermolabile MTHFR was absent in those 677TThomozygote individuals who carried an additional $C B S$ 844ins68 allele (de Stefano et al. 1998; Tsai et al. 1999). In contrast to initial concepts (Sebastio et al. 1995), the insertion creates an alternative splice site eliminating both sequence variants, $833 \mathrm{~T} \rightarrow \mathrm{C}$ and 844ins68, resulting in normal mRNA and enzyme (Tsai et al. 1996). At present, it is not clear how the observed homocysteine-lowering effect is produced in these individuals. In any case, $C B S 844$ ins 68 obviously is not responsible for elevated homocysteine levels. Therefore, $C B S$ 844ins68 seems not to be a good candidate for NTD in connection with hyperhomocysteinemia.

Acknowledgments We would like to thank the patients and their families for cooperating in this study. We thank Christopher Schwarz for technical assistance. The work was supported by the Deutsche Forschungsgemeinschaft, Bonn, and the organization ARQUE, Mainz.

\section{References}

Akar N, Akar E, Deda G, Arsan S (2000) Spina bifida and common mutations at the homocysteine metabolism pathway. Clin Genet 57:230-231

Barber R, Shalat S, Hendricks K, Joggerst B, Larsen R, Suarez L, Finnell R (2000) Investigation of folate pathway gene polymorphisms and the incidence of neural tube defects in a Texas Hispanic population. Mol Genet Metab 70:45-52

Berry RJ, Li Z, Erickson JD, Li S, Moore CA, Wang H, Mulinare J, Zhao P, Wong L-YC, Gindler J, Hong SX, Correa A (1999) Prevention of neural-tube defects with folic acid in China. N Engl J Med 341:1485-1490

Boduroglu K, Alikasifoglu M, Anar B, Tuncbilek E (1999) Association of the $677 \mathrm{C} \rightarrow \mathrm{T}$ mutation on the methylenetetrahydrofolate reductase gene in Turkish patients with neural tube defects. J Child Neurol 14:159-161

Botto LD, Yang Q (2000) 5,10-Methylenetetrahydrofolate reductase gene variants and congenital anomalies: a HuGE review. Am J Epidemiol 151:862-877

Czeizel AE, Dudás I (1992) Prevention of the first occurrence of neural-tube defects by periconceptional vitamin supplementation. N Engl J Med 327:1832-1835

de Franchis R, Buoninconti A, Mandato C, Pepe A, Sperandeo MP, Del Gado R, Capra V, Salvaggio E, Andria G, Mastroiacovo P (1998) The C677T mutation of the 5,10-methylenetetrahydrofolate reductase gene is a moderate risk factor for spina bifida in Italy. J Med Genet 35:1009-1013

de Franchis R, Mandato C, Buoninconti A, Sperandeo MP, Capra V, De Marco P, Ricci R, Mastroiacovo P, Selvaggio E, Sebastio G, Andria G (1997) Risk factors for neural tube defects: analysis of common genetic variants of methylenetetrahydrofolate reductase and cystathionine $\beta$-synthase (abstract). Am J Hum Genet 61:151 
de Stefano V, Dekou V, Nicaud V, Chasse JF, London J, Stansbie D, Humphries SE, Gudnason V (1998) Linkage disequilibrium at the cystathionine $\beta$-synthase (CBS) locus and the association between genetic variation at the CBS locus and plasma levels of homocysteine. Ann Hum Genet 62:481-490

Fleming A, Copp AJ (1998) Embryonic folate metabolism and mouse neural tube defects. Science 280:2107-2109

Fletcher O, Kessling AM (1998) MTHFR association with arteriosclerotic vascular disease? Hum Genet 103:11-21

Franco RF, Elion J, Lavinha J, Krishnamoorthy R, Tavella M, Zago M (1998) Heterogenous ethnic distribution of the 844ins68 in the cystathionine $\beta$-synthase gene. Hum Hered 48:338-342

Frosst P, Blom HJ, Milos R, Goyette P, Sheppard CA, Matthews RG, Boers GJH, den Heijer M, Kluijtmans LAJ, van den Heuvel LP, Rozen R (1995) A candidate genetic risk factor for vascular disease: a common mutation in methylenetetrahydrofolate reductase. Nature Genet 10:111-113

Heid MK, Bills ND, Hinrichs SH, Clifford AJ (1992) Folate deficiency alone does not produce neural tube defects in mice. J Nutr 122:888894

Jacques PF, Bostrom AG, Williams RR, Ellison RC, Eckfeldt JH, Rosenberg IH, Selhub J, Rozen R (1996) Relation between folate status, a common mutation in methylenetetrahydrofolate reductase, and plasma homocysteine concentrations. Circulation 93:7-9

Kang S-S, Zhou J, Wong PWK, Kowalisyn J, Strokosch G (1988) Intermediate homocysteinemia: a thermolabile variant of methylenetetrahydrofolate reductase. Am J Hum Genet 43:414-421

Kozich V, Kraus JP (1992) Screening for mutations by expressing patient cDNA segments in E. coli: homocysteinuria due to cystathionine $\beta$-synthase deficiency. Hum Mut 1:113-123

Kraus JP, Oliveriusová J, Sokolová J, Kraus E, Vlcek C, de Franchis R, Maclean KN, Bao L, Bukovská G, Patterson D, Paces V, Ansorge W, Kozich V (1998) The human cystathionine $\beta$-synthase (CBS) gene: complete sequence, alternative splicing, and polymorphisms. Genomics 52:312-324

Mills JL, McPartlin JM, Kirke PN, Lee YJ, Conley MR, Weir DG, Scott JM (1995) Homocysteine metabolism in pregnancies complicated by neural-tube defects. Lancet 345:149-151

Mills JL, Scott JM, Kirke PN, McPartlin JM, Conley MR, Weir DG, Molloy AM, Lee YJ (1996) Homocysteine and neural tube defects. J Nutr 126:756S-760S

Molloy AM, Daly S, Mills JL, Kirke PN, Whitehead AS, Ramsbottom D, Conley MR, Weir DG, Scott JM (1997) Thermolabile variant of 5,10-methylenetetrahydrofolate reductase associated with low redcell folates: implications for folate intake recommendations. Lancet 349:1591-1593

Mornet E, Muller F, Lenvoisé-Furet A, Delezoide A-L, Col J-Y, Simon-Bouy B, Serre J-L (1997) Screening of the C677T mutation on the methylenetetrahydrofolate reductase gene in French patients with neural tube defects. Hum Genet 100:512-514

Morrison K, Papapetrou C, Hol FA, Mariman ECM, Lynch SA, Burn J, Edwards YH (1998) Susceptibility to spina bifida; an association study of five candidate genes. Ann Hum Genet 62:379-396

MRC Vitamin Study Research Group (1991) Prevention of neural tube defects: results of the Medical Research Council Vitamin Study. Lancet 338:131-137

Pepe G, Vanegas OC, Rickards O, Giusti B, Comeglio P, Brunelli T, Marcucci R, Prisco D, Gensini GF, Abbate R (1999) World distribution of the T833C/844INS68 CBS in cis double mutation: a reliable anthropological marker. Hum Genet 104:126-129

Piedrahita JA, Oetama B, Bennett GD, van Waes J, Kamen BA, Richardson J, Lacey SW, Anderson RGW, Finnell RH (1999) Mice lacking the folic acid-binding protein Folbp1 are defective in early embryonic development. Nature Genet 23:228-232

Ramsbottom D, Scott JM, Molloy A, Weir DG, Kirke PN, Mills JL, Gallagher PM, Whitehead AS (1997) Are common mutations of cystathionine $\beta$-synthase involved in the aetiology of neural tube defects? Clin Genet 51:39-42
Rosenquist TH, Ratashak SA, Selhub J (1996) Homocysteine induces congenital defects of the heart and neural tube: effect of folic acid. Proc Natl Acad Sci USA 93:15227-15232

Sebastio G, Sperandeo MP, Panico M, de Franchis R, Kraus JP, Andria G (1995) The molecular basis of homocysteinuria due to cystathionine $\beta$-synthase deficiency in Italian families, and report of four novel mutations. Am J Hum Genet 56:1324-1333

Shaw GM, Rozen R, Finnell RH, Wasserman CR, Lammer EJ (1998) Maternal vitamin use, genetic variation of infant methylenetetrahydrofolate reductase, and risk for spina bifida. Am J Epidemiol 148:30-37

Shields DC, Kirke PN, Mills JL, Ramsbottom D, Molloy AM, Burke H, Weir DG, Scott JM, Whitehead AS (1999) The "thermolabile" variant of methylenetetrahydrofolate reductase and neural tube defects: an evaluation of genetic risk and the relative importance of the genotypes of the embryo and the mother. Am J Hum Genet 64:10451055

Speer M, Nye J, McLone D, Worley G, Melvin EC, Viles KD, Franklin A, Drake C, Mackey J, George TM, NTD Collaborative Group (1999) Possible interaction of genotypes at cystathionine $\beta$-synthase and methylenetetrahydrofolate reductase (MTHFR) in neural tube defects. Clin Genet 56:142-144

Speer MC, Worley G, Mackey JF, Melvin E, Oakes WJ, George TM, NTD Collaborative Group (1997) The thermolabile variant of methylenetetrahydrofolate reductase (MTHFR) is not a major risk factor for neural tube defect in American Caucasians. Neurogenetics 1:149-150

Stegmann K, Ziegler A, Ngo ETKM, Kohlschmidt N, Schröter B, Ermert A, Koch MC (1999) Linkage disequilibrium of MTHFR genotypes $677 \mathrm{CT} / 1298 \mathrm{AC}$ in the German population and association studies in probands with neural tube defects (NTD). Am J Med Genet 87:23-29

Sun F, Flanders WD, Yang Q, Khoury MJ (1999) Transmission disequilibrium test (TDT) when only one parent is available: the 1-TDT. Am J Epidemiol 150:97-104

Trembath D, Sherbondy AL, Vandyke DC, Shaw GM, Todoroff K, Lammer EJ, Finnell RH, Marker S, Lerner G, Murray JC (1999) Analysis of select folate pathway genes, $P A X 3$, and human $T$ in a midwestern neural tube defect population. Teratology 59:331-341

Tsai MY, Bignell M, Schwichtenberg K, Hanson NQ (1996) High prevalence of a mutation in the cystathionine $\beta$-synthase gene. Am J Hum Genet 59:1262-1267

Tsai MY, Yang F, Bignell M, Aras O, Hanson NQ (1999) Relation between plasma homocysteine concentration, the 844ins68 variant of the cystathionine $\beta$-synthase gene, and pyridoxal-5'-phosphate concentration. Mol Genet Metab 67:352-356

van der Put NMJ, Gabreels F, Stevens EMB, Smeitink JAM, Trijbels FJM, Eskes TKAB, van den Heuvel LP, Blom HJ (1998) A second common mutation in the methylenetetrahydrofolate reductase gene: an additional risk factor for neural-tube defects? Am J Hum Genet 62:1044-1051

van der Put NMJ, Steegers-Theunissen RPM, Frosst P, Trijbels FJM, Eskes TKAB, van den Heuvel LP, Mariman ECM, den Heyer M, Rozen R, Blom HJ (1995) Mutated methylenetetrahydrofolate reductase as a risk factor for spina bifida. Lancet 346:1070-1071

Weisberg I, Tran P, Christensen B, Sibani S, Rozen R (1998) A second genetic polymorphism in methylenetetrahydrofolate reductase (MTHFR) associated with decreased enzyme activity. Mol Genet Metab 64:169-172

Whitehead AS, Gallagher P, Mills JL, Kirke PN, Burke H, Molloy AM, Weir DG, Shields DC, Scott JM (1995) A genetic defect in 5,10methylenetetrahydrofolate reductase in neural tube defects. Q J Med 88:763-766

Zhao Q, Behringer RR, de Crombrugghe B (1996) Prenatal folic acid treatment suppresses acrania and meroanencephaly in mice mutant for the Cart1 homeobox gene. Nature Genet 13:275-283 